\title{
Utility of gastric aspirates in screening for pulmonary tuberculosis in high risk subjects:The Manitoba experience
}

\author{
A Bahammam MD MRCP (UK), SH Choudhri MD FRCPC, R Long MD FRCPC
}

\begin{abstract}
A Bahammam, SH Choudhri, R Long. Utility of gastric aspirates in screening for pulmonary tuberculosis in high risk subjects: The Manitoba experience. Can J Infect Dis 1999;10(1):69-73.

BACKGROUND: Although gastric aspirates (GA) are one of the recommended screening procedures for asymptomatic individuals at high risk for developing tuberculosis (TB), little data exist on the utility of GA for this indication. OBJECTIVE: To determine the utility of GA as a screening tool in asymptomatic subjects who are at high risk for developing pulmonary TB.

PATIENTS AND METHODS: The study population's clinical, radiographical and Mantoux skin test findings were correlated with a laboratory database of all patients who underwent GA in 1994. Subjects included in the study were those at high risk of developing TB, ie, immigrants placed under surveillance for TB postlanding in Canada (surveillance foreign-born), other foreign-born individuals from high prevalence countries, Status Indians and close contacts of patients with active pulmonary TB.

RESULTS: Four hundred and twelve GAs were performed in 318 patients. Complete data were available in 243 patients. Canadian-born persons who were not Status Indians and foreign-born persons from nonendemic areas $(n=37)$ were excluded. The remaining 206 patients had $261 \mathrm{GAs}$ performed (1.27 \pm 0.7 per subject). This group consisted of surveillance foreign-born $(n=57)$, other foreign-born $(n=110)$ and Status Indians $(n=39)$. Fifty-three $(26 \%)$ were symptomatic and $153(74 \%)$ were asymptomatic. Ninety-eight had a normal chest radiograph, and 108 had an abnormal chest radiograph. Fourteen subjects (26\%) in the symptomatic group had Mycobacterium tuberculosis isolated from their GA versus one $(0.65 \%)$ in the asymptomatic group $(\mathrm{P}<0.001)$. One subject $(1 \%)$ in the normal chest radiograph group versus $14(12 \%)$ in the abnormal chest radiograph group $(\mathrm{P}=0.005)$ had $M$ tuberculosis isolated from their GA. Thirty-six subjects were both symptomatic and had abnormal chest radiographs. In this group, 12 (33\%) had $M$ tuberculosis isolated from their GA, while none of the patients who were asymptomatic and had normal chest radiographs had a positive $M$ tuberculosis culture. There was no difference in the yield of GA between Mantoux skin test-positive and Mantoux skin test-negative groups.

CONCLUSIONS: GAs have a low yield when used to screen asymptomatic high risk subjects. The results suggest that screening of asymptomatic individuals or those with normal chest radiographs may not be warranted. This will spare many asymptomatic subjects the discomfort of undergoing the procedure and produce a significant cost saving.
\end{abstract}

Key Words: Gastric Aspirate, Screening, Tuberculosis

Pour le résumé, voir page 70

Department of Medicine, University of Manitoba, Winnipeg, Manitoba

Correspondence and reprints: Dr Shurjeel Choudhri, Section of Infectious Diseases, St Boniface General Hospital, C5127 - 409 Tache Avenue, Winnipeg, Manitoba R2H 2A6. Telephone 204-237-2948, fax 204-233-7125, e-mail schoudr@cc.umanitoba.ca

Received for publication January 7, 1998. Accepted June 2, 1998 


\title{
Utilité du tubage gastrique dans le dépistage de la tuberculose pulmonaire chez les sujets à risque élevé : l'expérience du Manitoba
}

\begin{abstract}
HISTORIQUE : Même si le tubage gastrique (TG) est l'un des procédés de dépistage recommandé chez des sujets asymptomatiques à risque élevé de développer une tuberculose (TB), il y a peu de données sur l'utilité du TG pour cette indication

OBJECTIF : Déterminer l'utilité du TG comme outil de dépistage chez les sujets asymptomatiques à risque élevé de TB pulmonaire.

PATIENTS ET MÉTHODES : Les résultats au test de Mantoux, aux épreuves cliniques et radiologiques de la population à l'étude ont été corrélés avec une base de données de laboratoire de tous les patients qui ont subi un TG en 1994. Les sujets inclus dans l'étude étaient ceux à risque élevé de TB pulmonaire, comme les immigrants placés sous surveillance pour raison de TB après leur arrivée au Canada (surveillance des sujets nés à l'étranger), d'autres individus nés à l'étranger venant de pays à forte prévalence de TB ainsi que les Indiens enregistrés et l'entourage des malades atteints d'une TB pulmonaire évolutive.

RÉSULTATS : Quatre cent douze prélèvements par TG ont été pratiqués chez 318 patients. Des données complètes étaient disponibles chez 243 patients. Les personnes nées au Canada qui n'étaient pas des Indiens enregistrés et les personnes nées à l'étranger dans des régions non endémiques pour la TB $(n=37)$ ont été exclues de l'étude. Deux cent soixante et un TG $(1,27 \pm$ 0,7 par sujet) ont été pratiqués chez les 206 patients restants. Ce groupe comprenait les sujets nés à l'étranger sous surveillance $(n=57)$, d'autres sujets nés à l'étranger $(n=110)$ et les Indiens enregistrés $(n=39)$. Cinquante-trois sujets $(26 \%)$ étaient symptomatiques et $153(74 \%)$ asymptomatiques. La radiographie pulmonaire était normale chez 98 sujets et anormale chez 108 d'entre eux. Mycobacterium tuberculosis a été isolé dans les échantillons gastriques de quatorze sujets (26\%) du groupe symptomatique et chez un sujet $(0,65 \%)$ du groupe asymptomatique $(\mathrm{p}<0,001)$. On a isolé $M$. tuberculosis dans les échantillons gastriques chez un sujet (1\%) appartenant au groupe avec radiographie pulmonaire normale par rapport à 14 sujets $(12 \%)$ du groupe avec radiographie pulmonaire anormale $(p=0,005)$. Trente-six sujets étaient non seulement symptomatiques mais présentaient également des radiographies pulmonaires anormales. Dans ce groupe, on a isolé $M$. tuberculosis dans les échantillons gastriques de 12 sujets (33\%) tandis qu'aucune culture n'était positive pour $M$. tuberculosis chez les patients asymptomatiques et montrant des radiographies pulmonaires normales. Il n'y avait aucune différence dans le rendement des échantillons gastriques prélevés par tubage entre le groupe montrant un test de Mantoux positif et celui montrant un test de Mantoux négatif.

CONCLUSIONS : Les échantillons gastriques prélevés par TG ont un faible rendement quand ils sont utilisés pour dépister les sujets asymptomatiques à risque élevé. Les résultats permettent de croire que le dépistage des individus asymptomatiques ou ceux dont les radiographies pulmonaires sont normales pourrait être injustifié. Ceci épargnera à de nombreux sujets asymptomatiques le désagrément de subir cet examen et entraînera des économies substantielles.
\end{abstract}

$\mathrm{T}$ he past decade has seen a resurgence of tuberculosis (TB) in the United States (1). Similarly, TB case rates have failed to decline as expected in Canada (2). These developments have led to a renewed emphasis upon the clinical (3) and laboratory diagnosis of TB. Isolation of Mycobacterium tuberculosis from respiratory secretions remains the definitive diagnostic test for pulmonary TB because, in addition to providing diagnostic confirmation, isolation of the organism allows for drug susceptibility testing and DNA fingerprinting to identify patterns of TB transmission (4). Because many patients with early pulmonary TB are unable to produce sputum, alternate specimens such as gastric aspirates (GAs) or induced sputum are often obtained for mycobacterial culture. It is possible to isolate $M$ tuberculosis from GA specimens because tubercle bacilli originating from the respiratory tract may, through cough or mucociliary clearance, reach the oropharynx where they are swallowed and enter the stomach. Although gastric acid can inhibit the growth of mycobacteria, the organisms usually remain viable and can be cultured.

The published literature on GAs has focused on two specific issues: the validity of acid fast stain of GA (5-8) and the comparison of GA cultures with those of spontaneous sputa or induced sputa in the bacteriological diagnosis of pulmonary tuberculosis $(6,7)$. Although this procedure is recommended for screening high risk groups such as foreign-born persons who are placed under surveillance for tuberculosis after landing in Canada (9), there are little data on the usefulness of this approach.

Despite the lack of published data, GAs have been used ex- tensively in Manitoba for both diagnosis and screening of tuberculosis in high risk persons who are unable to produce a sputum specimen. In Manitoba, over 400 GAs are performed annually in such patients at a cost of $\$ 34$ per procedure. We reviewed our experience with GAs over one year to determine the utility of this procedure in screening asymptomatic persons who are at high risk for developing TB.

\section{PATIENTS AND METHODS}

The Health Sciences Center (HSC) mycobacteriology laboratory, Winnipeg, Manitoba, is the reference laboratory for mycobacteriology in the province of Manitoba. All provincial specimens are ultimately sent to this laboratory for analysis, giving researchers the ability to explore the role of GAs in the diagnosis of pleuropulmonary mycobacterial disease. A laboratory database was used to retrieve information on all specimens submitted to the provincial mycobacterial laboratory (HSC) for mycobacterial smears and cultures. Using this database, the original records of the mycobacterial laboratory and a review of the patient's health records, a standardized data form was completed that included demographic, clinical, radiographical and laboratory information on all patients who underwent a GA for mycobacterial culture in 1994.

Study population: The patients were divided into three groups. The first group consisted of surveillance foreign-born individuals who were placed under surveillance for tuberculosis after entering in Canada (9) in 1994 because of abnormal chest radiographs, clinical suspicion of pulmonary TB or a prior history of TB. The decision to screen these individuals 
was made by the Canadian immigration authorities and not by this centre. The other two groups were foreign-born individuals from endemic areas who immigrated to Canada before 1994 and were not under surveillance, and Status Indians.

Patients at high risk for developing TB were defined as those who were foreign-born and had immigrated to Canada from an endemic area, Status Indians and close contacts (ie, those sharing the same household or other enclosed environments) of persons known or suspected to have TB (10). Southeast Asia, the Indian subcontinent, the Middle East, Africa and South America were considered endemic areas for the purposes of this study.

The last two groups (other foreign-born and Status Indians) were referred for GA because of clinical or radiographical findings suggestive of pulmonary tuberculosis in the absence of productive cough, recent contact with patients with active pulmonary tuberculosis or tuberculin positive individuals (10 $\mathrm{mm}$ induration or greater) who were thought to be recent converters. Canadian-born persons who were not Status Indians and foreign-born persons from nonendemic areas (The United States, Western Europe) were excluded.

The presence or absence of symptoms and the presence or absence of abnormal chest radiographs subdivided each group further. Individuals were considered symptomatic if they had one or more of the following symptoms - fever, night sweats, cough, hemoptysis, chest pain or weight loss - and asymptomatic if they had none of the above. Chest radiographs were considered abnormal if there was apical scarring, parenchymal infiltrate, cavitary disease, evidence of pleural abnormalities including pleural effusion or lymph node enlargement according to the interpretations of the radiologist and/or the respirologist at the time of screening.

Specimen processing: All specimens were inoculated in Bactec-12B bottles (radiometric detection) (Becton Dickinson, Maryland) and Lowenstein-Jensen slants (BBL, Becton Dickinson), and incubated for eight weeks at a temperature of $37^{\circ} \mathrm{C}$ with $5 \%$ to $10 \%$ carbon dioxide.

Follow-up of study population: In Manitoba, all cases of active tuberculosis are reported to the Manitoba Central Tuberculosis Registry (CTR). The CTR records of the cohort in this study were reviewed one year after their initial visit to the clinic to determine if they had developed pleuropulmonary tuberculosis since the initial screening procedure.

Data analysis: Values were expressed as mean SD. The statistical significance of discrete variables was assessed by $\chi^{2}$ or Fisher-exact test and by nonparametric statistics (MannWhitney test) for ordinal variables. $\mathrm{P}=0.05$ was considered significant.

\section{RESULTS}

Four hundred and twelve GAs were performed in 318 patients; complete information was available for 243 patients. None of the 75 excluded patients had a positive GA culture for mycobacteria. Nonforeign-born Canadians and foreign-born persons from nonendemic areas were excluded $(n=37)$ because of the low risk of developing TB in this group. The remaining 206 subjects had 261 GAs (1.27 0.7 per subject).
TABLE 1

Demographics of study population

\begin{tabular}{lcccc}
\hline & $\begin{array}{c}\text { Surveillance } \\
\text { foreign-born } \\
\mathbf{n = 5 7}(\%)\end{array}$ & $\begin{array}{c}\text { Other } \\
\text { foreign-born } \\
\mathbf{n = 1 1 0}(\%)\end{array}$ & $\begin{array}{c}\text { Status } \\
\text { Indians } \\
\mathbf{n = 3 9}(\%)\end{array}$ & $\mathbf{P}^{*}$ \\
\hline $\begin{array}{c}\text { Age (years, } \\
\text { mean } \pm \text { SD) }\end{array}$ & $44.6 \pm 18$ & $42.5 \pm 16$ & $28 \pm 22$ & $\mathrm{P}<0.001$ \\
$\begin{array}{c}\text { Sex } \\
\text { Males }\end{array}$ & $29(51)$ & $48(44)$ & $25(64)$ & \\
$\begin{array}{c}\text { Females } \\
\text { Past history of } \\
\text { tuberculosis }\end{array}$ & $28(49)$ & $62(56)$ & $14(36)$ & \\
$\begin{array}{c}\text { Tuberculosis } \\
\text { contacts }\end{array}$ & N/A & 23 & 7 & \\
*Status Indians compared with all foreign-born subjects &
\end{tabular}

*Status Indians compared with all foreign-born subjects

This group consisted of recent immigrants who were referred from the immigration office for surveillance (surveillance foreign-born persons, $n=57$ ), other foreign-born persons from endemic areas $(n=110)$ and Status Indians $(n=39)$. The demographics of the study population are summarized in Table 1. Status Indians were significantly younger than the other two groups $(\mathrm{P}<0.001)$ and were more likely to be male. Subjects in the surveillance foreignborn category were more likely to have a past history of TB (39\%) compared with other foreign-born persons $(21 \%)$ and the Status Indian group (18\%). Not surprisingly, 29 (51\%) surveillance foreign-born individuals and 23 (21\%) other foreignborn subjects reported a past history of tuberculosis. Almost half (18 of 39, 46\%) of the Status Indians were screened after a recent TB contact compared with 30 of $110(27 \%)$ in the other foreign-born group.

of the 206 screened subjects, 15 had $M$ tuberculosis isolated from GAs $(7.3 \%)$. The remaining subjects $(n=191)$ had negative cultures and remained free of TB one year after their initial visit. The 15 patients with positive $M$ tuberculosis cultures underwent 1.60 .9 GAs per patient compared with 1.260 .65 in subjects with negative cultures $(P=0.15)$. On reviewing the individual records of patients with positive $M t u$ berculosis cultures from GAs, we found that in all but one patient, $M$ tuberculosis was isolated from the first GA and the remaining tests were obtained for follow-up.

Symptoms: Among the 206 subjects, 53 (26\%) were symptomatic (duration of symptoms 20.220 .9 weeks) and 153 (74\%) were asymptomatic. In the symptomatic group, 14 (26\%) subjects had $M$ tuberculosis isolated from a GA versus one subject $(0.65 \%)$ in the asymptomatic group $(\mathrm{P}<0.001)$. Assuming that all 75 excluded patients were symptomatic and met the inclusion criteria, the difference between the yield of GA in symptomatic and asymptomatic persons remained significant $(\mathrm{P}<0.001)$. The relationship between symptoms and GA positivity for $M$ tuberculosis in each group is shown in Table 2.

No $M$ tuberculosis isolates were identified by GA in either symptomatic and asymptomatic surveillance foreign-born individuals, while in the other foreign-born and Status Indian groups, symptomatic subjects were significantly more likely 
TABLE 2

Relationship between gastric aspirate positivity for Mycobacterium tuberculosis and symptoms in each group

\begin{tabular}{|c|c|c|c|c|c|c|}
\hline \multirow[b]{2}{*}{ Gastric aspirate results } & \multicolumn{2}{|c|}{ Surveillance foreign-born $(n=57)$} & \multicolumn{2}{|c|}{ Other foreign-born $(n=110)$} & \multicolumn{2}{|c|}{ Status Indian $(n=39)$} \\
\hline & Symptomatic & Asymptomatic & Symptomatic & Asymptomatic & Symptomatic & Asymptomatic \\
\hline Positive & 0 & 0 & 7 & 1 & 7 & 0 \\
\hline Negative & 6 & 51 & 16 & 86 & 17 & 15 \\
\hline$P$ & & & \multicolumn{2}{|c|}{$<0.001$} & \multicolumn{2}{|c|}{0.03} \\
\hline
\end{tabular}

TABLE 3

Relationship between the isolation rate of Mycobacterium tuberculosis from gastric aspirates and chest radiographs in each group

\begin{tabular}{|c|c|c|c|c|c|c|}
\hline \multirow[b]{2}{*}{ Gastric aspirate results } & \multicolumn{2}{|c|}{$\begin{array}{l}\text { Surveillance foreign-born }(n=57) \\
\text { chest x-ray }\end{array}$} & \multicolumn{2}{|c|}{$\begin{array}{l}\text { Other foreign-born }(n=110) \\
\text { chest } x \text {-ray }\end{array}$} & \multicolumn{2}{|c|}{$\begin{array}{l}\text { Status Indians }(n=39) \\
\text { chest x-ray }\end{array}$} \\
\hline & Normal & Abnormal & Normal & Abnormal & Normal & Abnormal \\
\hline Positive & 0 & 0 & 0 & 8 & 1 & 6 \\
\hline Negative & 22 & 35 & 58 & 44 & 17 & 15 \\
\hline $\mathrm{P}$ & & & \multicolumn{2}{|c|}{0.006} & \multicolumn{2}{|c|}{0.09} \\
\hline
\end{tabular}

TABLE 4

Correlation of chest radiograph findings and results of gastric aspirate (GA) culture

\begin{tabular}{lcc}
$\begin{array}{l}\text { Chest radiograph } \\
\text { abnormalities }\end{array}$ & $\begin{array}{c}\text { GA positive (\%) } \\
\mathbf{n = 1 5 *}\end{array}$ & $\begin{array}{c}\text { GA negative (\%) } \\
\mathbf{n = 1 9 1}\end{array}$ \\
\hline Cavity & $4(29.6)$ & $1(0.5)$ \\
Cystic changes & $3(21.4)$ & $3(1.6)$ \\
Alveolar infiltrate & $1(7.1)$ & $5(2.6)$ \\
Interstitial infiltrate & $4(29.6)$ & $36(18.8)$ \\
Mixed infiltrate & $7(50)$ & $14(7.3)$ \\
Pleural thickening & $3(21.4)$ & $17(8.9)$ \\
Pleural effusion & $1(7.1)$ & $2(1)$ \\
Mediastinal adenopathy & $1(7.1)$ & $6(3.1)$ \\
Gibbus & $1(7.1)$ & 0 \\
Nodule & $1(7.1)$ & $18(9.4)$ \\
\hline
\end{tabular}

*Some individuals had multiple chest radiograph abnormalities

to have a positive GA for $M$ tuberculosis $(\mathrm{P}<0.001$ and $\mathrm{P}<0.03$, respectively).

Chest radiograph findings: Chest radiographs were normal in 98 (48\%) of the study population and abnormal in 108 (52\%). In the group with a normal chest radiograph, only one subject (1\%) had $M$ tuberculosis isolated from a GA versus 14 (12\%) in the abnormal radiograph group $(\mathrm{P}=0.005)$. The individual with TB and a normal chest radiograph was symptomatic, having fever and night sweats.

The relationship between chest radiograph and GA positivity for $M$ tuberculosis in each group is shown in Table 3 . The chest radiograph findings of these patients are listed in Table 4 . While abnormal chest radiographs were associated with a higher probability of isolating $M$ tuberculosis from GA in the other foreign-born group $(\mathrm{P}=0.006)$, the difference was not significant among Status Indians $(\mathrm{P}=0.09)$. This may be related to the small number of subjects in this group.

Combined symptoms and chest radiograph findings: Thirty-six subjects had both symptoms and an abnormal chest radiograph. Of these, 12 (33\%) had $M$ tuberculosis isolated from a GA. Seventeen individuals had symptoms but normal chest radiographs, while 72 had abnormal chest radiographs in the absence of symptoms. In the 81 subjects who were asymptomatic and had normal chest radiographs, no cases of TB were identified $(\mathrm{P}<0.001)$.

Mantoux skin testing: The results of Mantoux tests were available for 100 subjects and unknown for 106 subjects. Ninety subjects had positive Mantoux skin test with a mean induration of $19.38 \mathrm{~mm}$. There were nine cases of tuberculosis in the Mantoux-positive group versus one case in the Mantoux-negative group $(\mathrm{P}=1.00)$.

\section{DISCUSSION}

A diagnosis of pulmonary tuberculosis may be suspected based upon the patient's epidemiological, clinical and radiographical picture as well as the findings on Mantoux skin testing, but $M$ tuberculosis has to be isolated from the respiratory secretions before a definitive diagnosis can be made. In this study, the utility of GA as a screening tool for pulmonary tuberculosis was examined in a high risk population, which included surveillance foreign-born (11) persons, other foreignborn individuals and Status Indians (12). The relationship between the clinical, radiographical and skin test findings and GA positivity was analyzed. We found that the yield of GA in individuals who were asymptomatic or who had a normal chest radiograph was only $0.65 \%$ and $1 \%$, respectively. The GA yield was significantly higher in individuals who were symptomatic $(26 \%)$ or had an abnormal chest radiograph $(14 \%)$ or both $(33 \%)$.

Mantoux skin test positivity did not predict the GA results in this study. In most subjects with a positive Mantoux skin test, it was difficult to determine if they were recent converters because documentation of their previous test status was not available. Because many may have been positive well before our study, the predictive value of a positive Mantoux was diluted.

None of the surveillance foreign-born individuals had pulmonary tuberculosis diagnosed by GA. Previous reports in Canada have shown that the isolation rate of $M$ tuberculosis 
using sputum and GA in this group at their first visit to the clinic range from $1.2 \%$ to $3 \%(13,14)$. Possible explanations for our findings include the prescreening of recent immigrants in their country of origin and treatment of patients with active tuberculosis as a precondition for admission to Canada (13), and the fact that most individuals in the surveillance foreignborn group were asymptomatic by history.

The recommendation to perform GA in all surveillance foreign-born persons stems from the concern that these individuals may not be able to provide a reliable clinical history. Our results suggest that this may not necessarily be the case. Patients who gave a history of having had TB were more likely to have an abnormal chest radiograph, while the absence of patient-reported symptoms was significantly correlated with a negative $M$ tuberculosis culture on GA.

Our findings show that screening subjects who are asymptomatic or have normal chest radiographs for tuberculosis has a low yield. Proper use of screening procedures such as GA by targeting patients who are symptomatic and/or have abnormal chest radiographs would spare many subjects the discomfort of undergoing the procedure, produce significant cost savings and an improvement in the yield of GA. Finally, reducing the patient's discomfort may improve their compliance with future surveillance.

The cost for obtaining a gastric aspirate in Manitoba is $\$ 34$. Because our study population underwent an average of 1.27 gastric aspirates, the total cost of obtaining GA in the 125 subjects with either symptoms or an abnormal chest radiograph (high risk group) was $\$ 5,400$ versus $\$ 3,500$ in the asymptomatic subjects with normal chest radiographs (low risk

\section{REFERENCES}

1. Bloom BR, Murray CJL. Tuberculosis: Commentary on a re-emergent killer. Science 1992;257:55-64

2. Fitzgerald M, ed. Canadian tuberculosis standards, 4th edn. Toronto: University of Toronto Press, 1995.

3. Corne S, Long R. The war against TB: clues to victory. Medicine: North Am March, 1995; 18:223-31.

4. Barnes P, Barrows SA. Tuberculosis in the 1990s. Ann Intern Med 1993;119:400-10.

5. Pratt PC, Atwell RJ. The diagnostic reliability of acid-fast bacilli demonstrated in aspirated gastric contents. Am Rev Respir Dis 1961;83:96-9.

6. Saslaw S, Perkins RL. The gastric smear for acid-fast bacilli demonstrated in aspirated gastric contents. Am J Med Sci 1962;243:470-4

7. Strumpf IJ, Tsang AY, Schork MA, et al. The reliability of gastric smears by auramine-rhodamine staining technique for the diagnosis of tuberculosis. Am Rev Respir Dis 1976;114:971-6.

8. Berean K, Roberts FJ. The reliability of acid-fast stained smears of gastric aspirate specimens. Tubercle 1988;69:205-8.

9. Guidelines for the investigation of individuals who were placed under surveillance for tuberculosis post-landing in Canada. Can Commun Dis Rep 1992;18-20:153-5. group). Because 15 of 125 subjects in the high risk group had a positive GA, the cost per positive GA was $\$ 360.00$. In comparison, none of the 81 subjects in the low risk group had a positive GA (cost per positive GA over $\$ 3,500$ ). Thus, screening just the high risk group based upon the presence of symptoms and/or an abnormal chest radiograph would have reduced the annual screening costs by approximately $35 \%$.

We are not implying that individuals from high risk groups who are asymptomatic or have normal chest radiographs do not have a risk of developing pleuropulmonary tuberculosis. Previous studies from Canada (13), the United States (15) and Britain (16) have shown that in newly arrived immigrants, most cases of tuberculosis occur in the first five years after arrival. We concur that these individuals should be followed clinically for the required surveillance period or until the surveillance physician makes a clinical decision not to pursue further follow up. Although GAs had an excellent negative predictive value, with no cases of TB being identified in GAnegative patients after one year of follow-up, our results suggest that this invasive screening procedure is unnecessary in patients who are asymptomatic and have normal chest radiographs.

Our findings are not intended to serve as a guideline for obtaining GAs. However, they do suggest that proper selection of patients for this procedure based on clinical and radiographical data would result in more effective utilization of the procedure and significant cost savings. Our results emphasize the need for a controlled prospective study to confirm these findings and to identify the subjects who will benefit most from screening procedures such as GA.

10. Screening for tuberculosis and tuberculosis infection in a high risk population. Recommendations of the Advisory Council for the Elimination of Tuberculosis. Morb Mortal Wkly Rep 1995;44:19-34.

11. Enarson DA, Ashley MJ, Grzybowski S. Tuberculosis in immigrants to Canada: A study of present-day patterns in relation to immigration trends and birthplace. Am Rev Respir Dis 1979;119:11-8.

12. Enarson DA, Grzybowski S. Incidence of active tuberculosis in the native population in Canada. Can Med Assoc J 1986;134:1149-52.

13. Orr PH, Manfreda J, Hershfield ES. Tuberculosis surveillance in immigrants to Manitoba. Can Med Assoc J 1990;142:453-8.

14. Wang JS, Allen EA, Enarson DA, Grzybowski S. Tuberculosis in recent Asian immigrants to British Columbia, Canada: 1982-1985. Tubercle 1991;72:277-83.

15. Powell KE, Meador MP, Farer LS. Foreign-born persons with tuberculosis in the United States. Am J Public Health 1981;71:1223-7.

16. Report from the British Thoracic and Tuberculosis Association. Tuberculosis among immigrants related to length of residence in England and Wales. Br Med J 1975;3:698-9. 


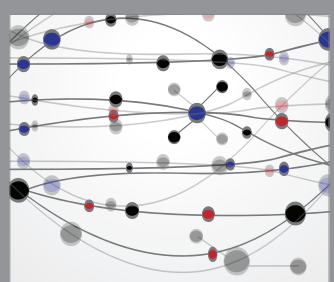

The Scientific World Journal
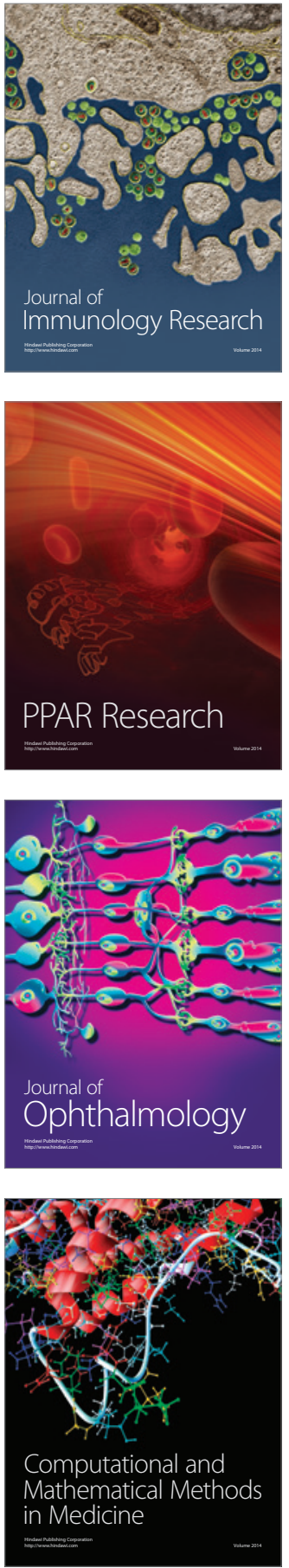

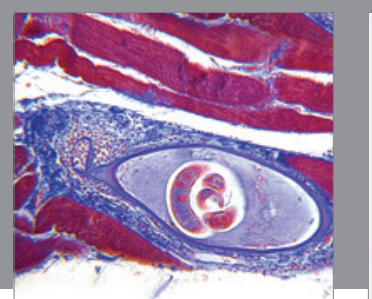

Gastroenterology Research and Practice

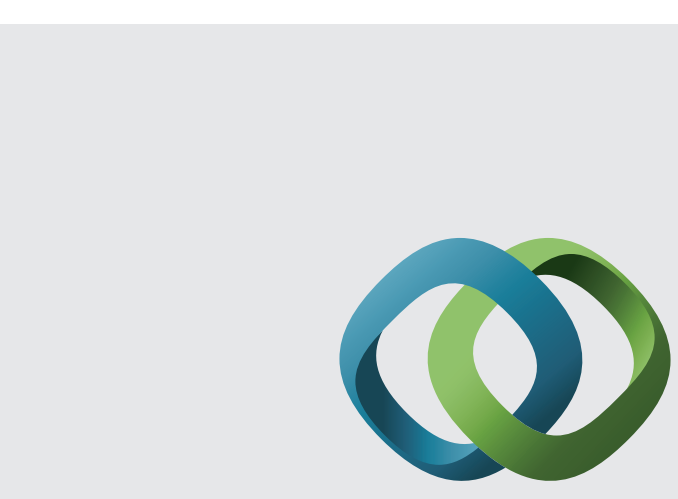

\section{Hindawi}

Submit your manuscripts at

http://www.hindawi.com

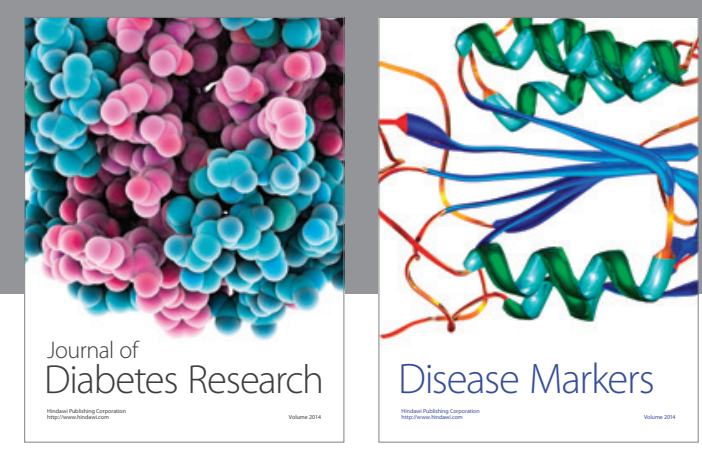

Disease Markers
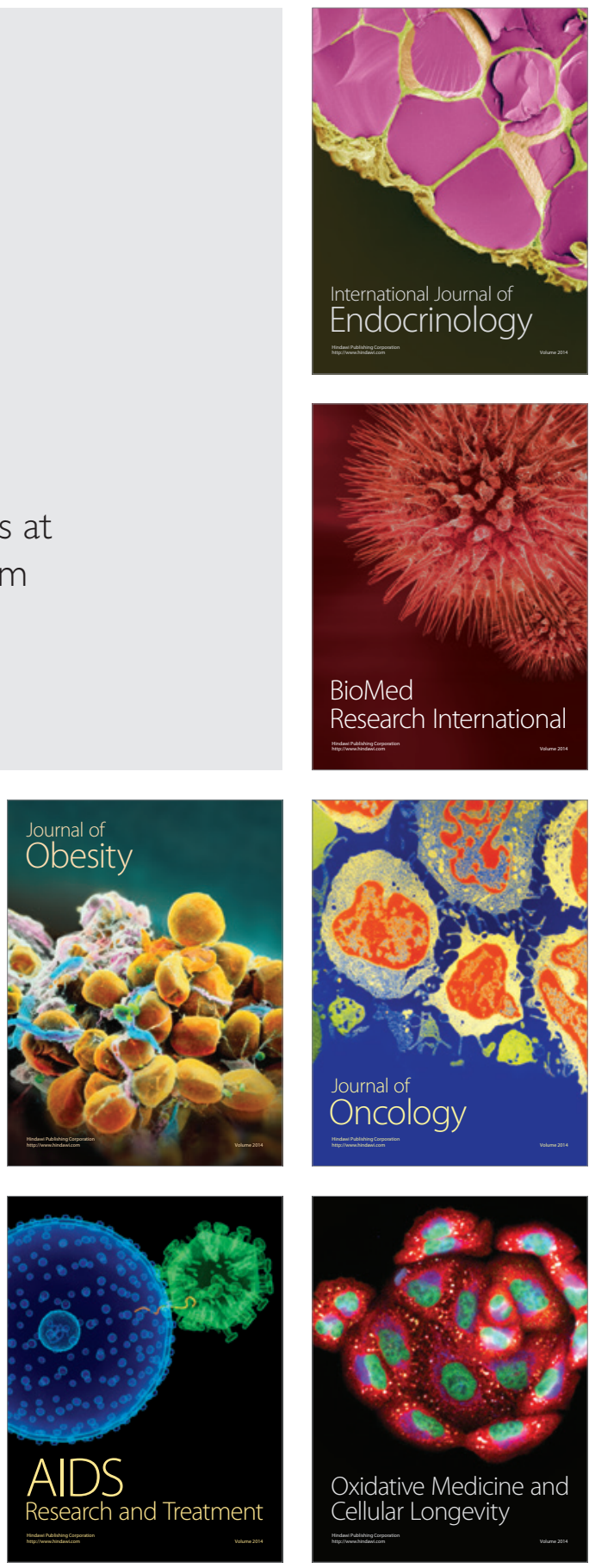